\title{
Protección del consumidor financiero en Colombia en el uso de canales electrónicos bancarios $^{1}$
}

\author{
Protection of the Financial Consumer in Colombia in the Use of Electronic Banking Channels
}

\author{
Celina Patricia Anaya Saade a \\ Universidad del Magdalena, Colombia \\ canaya@unimagdalena.edu.co \\ ORCID: https://orcid.org/0000-0002-2048-5581
}

DOI: https://doi.org/10.11144/Javeriana.vj69.pcms

Recibido: 24 Octubre 2019

Aceptado: 05 Noviembre 2019

Publicado: 17 Noviembre 2020

\section{Resumen:}

Este artículo es una reflexión analítica acerca de la protección del consumidor financiero en Colombia frente al uso de los canales electrónicos de servicios bancarios. Lo anterior, teniendo como base lo siguiente: en Colombia se han adoptado políticas de protección encaminadas a que el uso de canales electrónicos de servicios bancarios se realice en términos de seguridad y de confianza. Por ello, es necesario que tal protección sea pertinente, eficaz y que esté realmente cimentada en la información que le permita al consumidor saber en detalle el funcionamiento de estas operaciones, en términos de la instrumentalización de estas relaciones negociales, para desarrollar buenas prácticas en el manejo de canales de servicios financieros y la observancia del interés público. Se concluye que, en algunos casos de utilización de canales electrónicos, la protección que ofrece el banco no debe ser de "papel” porque desconoce la buena fe y la debida diligencia que enmarca la prestación de los servicios financieros de cara al consumidor.

Palabras clave: debida diligencia, buena fe, canales electrónicos, interés público.

\section{Abstract:}

This article is an analytical reflection on the protection of financial consumers in Colombia against the use of electronic channels of banking services. In Colombia, protection policies have been adopted to ensure the use of electronic channels of banking services is carried out in terms of security and trust. Therefore, for that protection to be relevant, effective and it is necessary that the instrumentalization of these business relationships is based on technical and legal information to developing good practices in the management of financial services channels and the public interest. It is concluded that, in some cases, when using electronic channels, the protection offered by the bank should not be limited to "paper" because it ignores the good faith and due diligence that frames the provision of financial services to the consumer.

Keywords: due diligence, good faith, electronic channels, public interest.

\section{Introducción}

La actividad bancaria en nuestro país despliega una gran labor para la economía nacional en relación a los productos y servicios que se ofrecen, por lo tanto, es necesario que exista un mayor acercamiento por parte de los consumidores de todo el marco legal y de los principios existentes para su protección, así como una labor exhaustiva por parte de las entidades vigiladas y del supervisor bancario para difundir y promover la protección del consumidor, en especial la relacionada con los canales electrónicos de servicios, que son utilizados con alta frecuencia por los usuarios.

Así pues, este artículo de reflexión es resultado de una investigación adelantada en el marco del proyecto titulado "Pertinencia de los mecanismos de protección legal del consumidor financiero en el uso de canales de distribución de productos y servicios del sector bancario en Colombia". Esta investigación utilizó una metodología documental a partir de la recopilación de información a través de la lectura y crítica de documentos y fuentes originales, tales como textos de doctrina nacional e internacional, artículos científicos,

Notas de autor 
jurisprudencia y textos normativos. Este artículo también se apoya en entrevistas realizadas en el marco de la investigación y la revisión de casos puntuales de la realidad del uso de canales electrónicos.

En la primera parte de este artículo se conceptualizarán los canales electrónicos de servicios bancarios con el propósito de conocer el alcance de su uso. En una segunda parte, se analizan los aspectos contractuales de relaciones jurídicas entre banco-cliente, y los que se ejecutan a través de los sistemas transaccionales de pago para analizar el alcance de los derechos y obligaciones de cara a la buena fe y la debida diligencia. Finalmente, se presenta una discusión, a manera de reflexión, sobre la actividad bancaria en canales electrónicos frente a la protección del consumidor financiero y, como aporte, se plantea que el comportamiento de las entidades financieras con respecto al uso de canales electrónicos y de cara al interés público podría ser mayor, en consonancia con los postulados previstos en el régimen de protección del consumidor financiero. De manera que tal protección sea evidente y no solo quede escrita en los reglamentos, circulares de la Superintendencia Financiera de Colombia y en la ley misma.

\section{Descripción de los canales de distribución de servicios financieros utilizados en los entornos electrónicos}

La evolución de los servicios que la banca ofrece al público ha sido posible gracias al desarrollo de la tecnología que hace más eficaz y seguro el uso de los sistemas y medios de pago ${ }^{2}$.

En Colombia, los bancos utilizan diferentes canales de distribución como las vías para proveer servicios y productos financieros a disposición de los clientes y usuarios.

De acuerdo a la circular externa $029^{3}$, se entiende como canales electrónicos de distribución de servicios ofrecidos por las entidades vigiladas, en particular aquellas que realizan intermediación financiera, a los siguientes: Cajeros Automáticos (ATM), Receptores de cheques, Receptores de dinero en efectivo, POS (incluye PIN Pad), Sistemas de Audio Respuesta (IVR), Centro de atención telefónica (Call Center, Contact Center), Sistemas de acceso remoto para clientes (RAS), Internet y Banca móvil.

Los requisitos de seguridad previstos para estos canales se encuentran contenidos en la circular externa 052 que impartió una serie de "requerimientos mínimos de seguridad y calidad en el manejo de la información a través de medios y canales de distribución de productos y servicios para clientes y usuarios" ${ }^{\circledR}$, la cual, a su vez, fue modificada por la circular externa 042 de 2012. Es importante aclarar que se hizo una delimitación temporal y se tuvieron en cuenta datos entre 2016 y 2017 para efectos de este estudio. Por lo tanto, se aclara que, si bien existe la circular externa 008 de 2018 de la Superfinanciera que entra en rigor el 1 de diciembre de 2018, esta no fue analizada porque los aspectos analizados en este escrito fueron dados con anterioridad a su expedición.

Para el uso de estos canales electrónicos se requiere de los medios de pago que son aquellos que permiten la realización de operaciones bancarias, tales como: dinero, cheques, y tarjetas débito y crédito ${ }^{5}$. Un sistema de pago, de acuerdo con el Decreto 1400 de 2005, hoy recogido en el Decreto 2555 de 2010, es todo conjunto organizado de políticas, reglas, instrumentos de pago, entidades y componentes tecnológicos como software, equipos y sistemas de comunicación a través de los cuales se realizan transferencias de fondos entre participantes, mediante la recepción, transmisión, procesamiento, compensación y/o liquidación de órdenes de transferencia y recaudo.

Ahora bien, ¿qué importancia representan estos canales y medios para la actividad bancaria? Estos instrumentos son necesarios para el pago de bienes y servicios en establecimientos de comercio y la disposición de fondos, ya sea en depósitos en cuenta corriente y/o de ahorros ${ }^{6}$.

Un ejemplo de un canal de distribución de servicios electrónicos novedoso con acogida en el sector bancario es el depósito electrónico, que es difundido por los bancos y que, de acuerdo con lo establecido por el Decreto 
2076 de 2015 incorporado en el Decreto Único 2555 de 20107 , se define como depósito a la vista, semejable a las cuentas de ahorro a nombre de personas naturales o jurídicas que deben tener unas condiciones específicas consagradas en dicha norma.

Lo anterior es una expresión del comercio electrónico entendida como la realización electrónica de transacciones comerciales entre las que se encuentran las operaciones de tipo financiero según la Ley 527 de $1999^{\circ}$. Para la entidad bancaria esto implica implementar todo un sistema tecnológico y de información con un grado alto de seguridad ${ }^{9}$ que dé al cliente o usuario la confianza para ejecutar sus operaciones y que estén dirigidas a la protección del consumidor financiero de cara a lo estipulado en la Ley 1328 de 2009 , que consagra la obligación para las entidades financieras de brindar productos y servicios en esquemas de seguridad que garanticen la tutela jurídica de los derechos de los consumidores.

A continuación, pasaremos a analizar los instrumentos jurídicos que son requeridos para el establecimiento de los derechos y obligaciones, tanto para el cliente como para el banco en Colombia ${ }^{10}$.

\section{Aspectos contractuales que reglamentan el uso de los canales electrónicos de servicios y la protección del consumidor financiero}

Con la Ley 1328 de 2009 se crea el régimen de protección al consumidor financiero, y con esta reforma se establecen normas sobre los aspectos propios de la relación negocial tales como la debida diligencia, que se traduce en el deber de ofrecer la información dirigida a la satisfacción de las necesidades del consumidor. La información debe ser realmente apropiada por el consumidor a fin de que este tenga plenitud de conocimiento sobre sus derechos y sus obligaciones en el uso de los canales electrónicos ${ }^{11}$.

Las relaciones jurídicas que se tejen entre los bancos y clientes se manifiestan a través de los contratos y los reglamentos correspondientes, de los que se derivan los correspondientes derechos y obligaciones para las partes que intervienen en la celebración de estos. Para efectos del presente análisis, únicamente enunciaremos la definición de los siguientes: la cuenta corriente, el depósito de ahorro y la apertura de crédito.

La cuenta corriente es uno de los contratos bancarios regulados en los artículos 1382 a 1392 del Código de Comercio, que se utiliza para hacer depósitos y retiros de dinero, se implementa el título valor denominado cheque y otorga al titular un contrato de apertura de crédito ${ }^{12}$. Este contrato también permite el uso de un canal electrónico a través de la tarjeta débito como medio de pago y elemento transaccional ${ }^{13}$.

El depósito de ahorro, o cuenta de ahorro, es un contrato que consiste en realización de depósitos irregulares de dinero cuyo deber genérico va dirigido a la devolución de las sumas depositadas y la custodia de los dineros por parte de los bancos ${ }^{14}$. En lo referente a la apertura de crédito, definida en el artículo 1400 del Código de Comercio, este permite el uso del medio de pago conocido como la tarjeta de crédito que es un instrumento de crédito con usos transaccionales y que sirve para realizar pagos, compras, avances en efectivo.

En virtud de que existe un marco regulatorio respecto de los instrumentos jurídicos utilizados para los canales electrónicos de servicios financieros, es importante destacar los esfuerzos dirigidos hacia la protección contractual y que debería reflejarse en el uso de canales electrónicos por parte del consumidor financiero, en especial al tener en cuenta lo expresado por Alejandro Rodríguez Zarate ${ }^{15}$ quien indica que el uso de estos entornos electrónicos se hace para maximizar las utilidades de los bancos, y en tal sentido debe existir esquemas dirigidos a garantizar la seguridad en el uso de los mismos.

Con la Ley 1328 de 2009, se le está dando preponderancia a los derechos y las obligaciones del consumidor financiero, tanto de parte de las entidades financieras como desde la supervisión estatal. A nivel global, la OCDE y el Banco Mundial plantean lo que se denomina como la "alfabetización financiera y el empoderamiento del consumidor" en la defensa de las políticas de protección del consumidor financiero, que tiene como objetivo que el consumidor se apropie de los conocimientos y destrezas en relación con el uso del 
producto y del servicio, que conozca los riesgos propios de la actividad, así como el ejercicio de sus derechos y obligaciones que emanan de las relaciones jurídicas ${ }^{16}$.

En ese esfuerzo colectivo de hacer que las políticas sean efectivas y que los principios que orientan la protección del consumidor financiero tengan real observancia, la Superintendencia Financiera de Colombia ha desarrollado una estructura importante que pretende lograr un mayor acercamiento del sistema al ciudadano, para enseñarle las herramientas y mecanismos que el Estado le ofrece para la protección de sus derechos como consumidores financieros.

Es por ello que en Colombia existe la Dirección de Protección al Consumidor Financiero como función de la Superintendencia Financiera de Colombia, cuya creación se encuentra inmersa en el Decreto 4327 de 2005 (hoy incorporado en el Decreto Único 2555 de 2010).

La estructura actual de la Delegatura para Protección al Consumidor Financiero se organiza en tres Divisiones: La Dirección de Conductas de Mercado, La Dirección de Prevención y La Dirección de Protección del Consumidor Financiero.

En esta última dirección se crearon tres Coordinaciones en el año 2016, de la cuales dos se encargan de conocer y atender las quejas y reclamos presentados por los usuarios en contra de los bancos, las aseguradoras, los fondos de pensiones y cesantías, las sociedades fiduciarias y la actividad de valores. La tercera Dirección está diseñada para la supervisión, la publicidad y la educación financiera.

Por otro lado, con la ley 1480 de 2011 se le otorga a la Superintendencia Financiera de Colombia funciones jurisdiccionales para conocer de los asuntos y conflictos relacionados con el consumidor financiero a través de la acción de protección del consumidor financiero, que ofrece un mecanismo expedito y ágil para dar solución a los conflictos que nacen de las relaciones entre clientes y los bancos. Sin duda alguna es un gran avance de cara a la protección del consumidor financiero en Colombia ${ }^{17}$.

Es así como se refleja la intervención del Estado a través del Supervisor, que es necesaria por ser una actividad de interés público según lo establecido en el artículo 335 de la Constitución Política, y que busca fortalecer la defensa del consumidor financiero en el marco de los instrumentos jurídicos creados para cuidar el equilibrio de las partes al establecer obligaciones recíprocas. Sin embargo, hay que tener siempre de presente que la celebración y ejecución de contratos, tales como el depósito de ahorro, la cuenta corriente o la apertura de crédito debe hacerse, en sintonía con lo que Neme Villarreal afirma ${ }^{18,}$ bajo la estricta observancia del principio de la buena fe, entendido como valor superior que nos ha enseñado la tradición romana, y que debe estar implícito desde el nacimiento del acuerdo de voluntades ${ }^{19}$ y durante la ejecución de las prestaciones. En especial si lo que se busca garantizar es que el equilibrio contractual ${ }^{20}$ de estas negociaciones, enmarcadas en el uso de canales de distribución electrónicos, no se vea afectado por las asimetrías en la información propias de la actividad financiera ${ }^{21}$.

Por lo anterior, conviene reflexionar sobre la utilización de los canales electrónicos en términos de buenas prácticas y un adecuado manejo.

\section{Reflexión sobre la actividad bancaria en canales electrónicos frente a la protección del consumidor financiero}

De cara a las implicaciones de la actividad bancaria considerada como de interés público ${ }^{22}$, en relación a las relaciones contractuales que se suscriben para los usos de canales electrónicos de servicios, llama la atención esta categoría de interés público porque estas relaciones jurídicas deben estar enmarcadas dentro de las reglas del principio de la buena fe, para garantizar la protección el consumidor financiero. El uso de estos canales requiere la realización de negocios jurídicos con derechos y obligaciones que deben armonizar con la buena 
fe contractual que establece la ley comercial ${ }^{23}$, y el deber de diligencia exigido en la Ley 1328 de 2009 para ambas partes: el banco que ofrece el servicio y el cliente consumidor financiero que lo recibe.

Además, la Ley exige que se cumpla con el deber de dar información, que, como sostiene Constanza Blanco Barón, es una herramienta para que el consumidor tome decisiones en forma libre y responsable ${ }^{24}$; y que le lleve al desarrollo de las buenas prácticas señaladas por la OCDE y la Arquitectura Financiera Internacional con respecto a la protección del consumidor financiero ${ }^{25}$.

Cambiar y colocar: En ese sentido, es necesario proveer al consumidor de información como el marco para el desarrollo armónico de la actividad bancaria. Es decir, proveer al consumidos de información como el marco general del contrato, los derechos y obligaciones, las consecuencias por el incumplimiento, las características y manejo claras de los productos y servicios, la seguridad en los canales de distribución de productos y servicios de los consumidores financieros y los inversionistas consumidores ${ }^{26}$, la presencia de cláusulas abusivas relacionadas con la exoneración de responsabilidad, y una publicidad veraz y completa que ofrezca y garantice la seguridad del consumidor.

Ahora bien, analicemos la siguiente situación que fue sometida a la Dirección de Asuntos Jurisdiccionales de la Superintendencia Financiera de Colombia en la que se logró terminar el conflicto por conciliación entre las partes, pero que vale la pena resaltar y exponer la negativa de la entidad ante la reclamación del consumidor financiero ${ }^{27}$.

El cliente utilizó el portal virtual del banco con el cual tiene una relación contractual y el producto contratado consistía en un cupo rotativo que se utilizaba a través del portal virtual, donde se hace un traslado de fondos desde el cupo de crédito a la cuenta de ahorros abierta para tal efecto. El cliente ingresó al portal, digitó su clave y encontró que no tenía saldo disponible. El cliente se pudo preguntar ¿qué pudo haber sucedido? Entonces, el consumidor pudo haberse enfrentado a las siguientes hipótesis:

1. Fallas en la sucursal bancaria.

2. La intervención de un tercero (hacker) en el uso del canal electrónico

3. Descuido en la utilización de claves secretos para acceder a los portales virtuales

Ante estas situaciones, podemos hacer el siguiente análisis:

Si se trató de la intervención de un tercero ¿por qué y cómo se hizo? ¿Acaso no hay seguridad en el uso de la sucursal bancaria? ¿Se puede utilizar información reservada y de uso exclusivo del cliente por terceros? o ¿Cuál debe ser la responsabilidad del banco frente a tales hechos? ¿Cómo se refleja la protección del consumidor por parte del banco ? $^{28}$

En un primer momento, la solución a estos planteamientos se encontró en las cláusulas que rigen los reglamentos bancarios de uso de canales electrónicos, que pueden contemplar por ejemplo el "traslado general" de responsabilidad al cliente por el uso indebido del canal. Sin embargo, esta cláusula no aplicaría ya que se ha confirmado que el único que conoce las claves secretas es el cliente, por tanto, esas transacciones solo pudieron ser realizadas por él.

Ahora bien, ¿qué se entiende por uso indebido? ¿Puede ser la utilización no autorizada de un canal electrónico por personas ajenas a la relación? En este caso, la problemática es la siguiente: ¿cómo se observa la protección del consumidor financiero?

A este respecto, puede señalarse lo siguiente:

El banco coloca a disposición del cliente y del usuario un canal electrónico para poder realizar las transacciones de traslado de fondos, consulta de saldos, retiro de dinero, etc. El banco debe garantizar al cliente unos requisitos mínimos de seguridad y calidad en la utilización del canal de distribución.

En este sentido, si bien el banco se ampara en la regulación y en el reglamento bancario, lo que está sucediendo actualmente (no en todos los casos), es que se traslada de forma absoluta la responsabilidad al cliente bajo el supuesto de que este es el dueño de los medios pago (tarjeta débito y tarjeta de crédito) y que es 
el único que tiene acceso a las claves secretas para la utilización de canales electrónicos, como ocurrió en el caso Heriberto Linero Roa vs. Bancoomeva S. A. que fue sometido a la Superintendencia Financiera de Colombia.

Desde nuestra propia perspectiva, la entidad, sin trasladar la carga de la prueba al cliente, debe valorar al menos lo siguiente: 1) si existió concurrencia de culpa por parte de cliente y un tercero ajeno a la entidad, 2) si la causa que originó la transacción no autorizada tuvo lugar en un hecho que escapa al control diligente por parte del cliente, 3) si existió intervención de un tercero, que vulneró la seguridad del medio electrónico.

El deber de realizar esta revisión de las posibilidades expuestas por parte del Banco encuentra su justificación en el hecho de que la actividad que realiza la banca es de interés público ${ }^{29}$, que se define como la característica que supone un límite a la autonomía de estas entidades financieras, en el sentido de que deben estar sometidas a un régimen especial ${ }^{30}$ que proteja y garantice la estabilidad y la continuidad de sus operaciones.

En otras palabras, a juicio propio, el concepto de interés público de la actividad bancaria significa que la esfera de su ejercicio no les compete única y exclusivamente a los agentes privados que intervienen en ella. Por su posición privilegiada, un banco debe observar reglas y principios generales que exigen un comportamiento especial, en razón a las consecuencias jurídicas y económicas que su actividad produzca y que pueda afectar eventualmente a terceros.

Esto se enlaza con la obligación a la absoluta observancia de la debida diligencia, considerada como un "esfuerzo por cumplir con la obligación" ${ }^{1}$, que se materializa al ofrecer la información necesaria para el uso del canal, pero que también se armoniza con la buena fe que debe tenerse en todas las fases de la contratación, formación y ejecución que se traducen en comportamientos propios de la actividad bancaria ${ }^{32}$. Todo esto en procura de una atención completa a la reclamación del cliente, que le permita conocer que sucedió con sus recursos a través de la sucursal bancaria que debería ofrecer seguridad, al partir del hecho de que el cliente cumplió con su deber de cuidado y diligencia en torno al uso del canal.

De esta manera, vale la pena reflexionar en lo siguiente:

¿Si el cliente que cumple con ese deber de custodia (de la clave secreta) llega ante el banco con esta situación de detrimento y lo que recibe por parte del banco es una respuesta negativa al aseverar que el canal electrónico fue seguro y que no existe responsabilidad del banco (sin hacer mayor valoración del caso), se encontrará realmente protegido como consumidor financiero?

Lo que se sostiene en esta reflexión es que ante una situación como la descrita anteriormente el proceder de la entidad bancaria debería ser el siguiente: realizar una revisión minuciosa del caso para identificar las fallas técnicas (si las hubo), o la posible intervención de un tercero. Esto, teniendo en cuenta los deberes generales de ambas partes: una atención al cliente sin inversión de la carga de la prueba como muestra de una buena práctica bancaria ${ }^{33}$.

En la realidad lo anterior no ocurre porque el banco se ciñe a lo que establece el reglamento, que traslada la responsabilidad al cliente en el uso del canal electrónico. En consecuencia, no va más a fondo de la situación para procurarle al cliente la solución de su caso cuando este ha actuado de buena fe y de manera diligente, sino que existe una presunción de mala fe de que el cliente permitió que el fraude se realizara y por ello debe asumir el riesgo de esa pérdida.

Sobre el particular es necesario plantear lo siguiente:

En Sentencia SC18614-2016 de 2016, proferida por la Corte Suprema de Justicia, se amplía el panorama respecto de la responsabilidad jurídica por parte de los bancos en los casos de fraudes con intervención de terceros y fundamentando el deber de la actividad bancaria y la característica de interés público, concluye lo siguiente:

"Se advierte que las entidades financieras deben asumir la responsabilidad por la defraudación sufrida por sus usuarios a través de transacciones electrónicas y reparar, en consecuencia, los perjuicios sufridos por estos actos. En efecto, se explica que ese riesgo es inherente a la actividad bancaria, la cual se caracteriza por ser profesional, habitual y lucrativa, cuya realización 
requiere, además, de altos estándares de diligencia, seguridad, control, confiabilidad y profesionalismo. Lo anterior conduce a la innegable e ineludible obligación de garantizar la seguridad de las transacciones que autoriza por cualquiera de los medios ofrecidos al público, con independencia de si los dineros sustraídos provienen de cuentas de ahorro o de cuentas corrientes. No obstante, se aclara que un banco puede exonerarse si prueba que el fraude ocurrió por culpa del cuentahabiente o que su actuar dio lugar al retiro de dinero de la cuenta, transferencias u otras operaciones que comprometieron sus recursos, pues si bien es el usuario quien tiene el control de los mecanismos que le permiten hacer seguimiento informático a las operaciones, a través de controles implantados en los software especializados con los que cuentan, se recuerda que la culpa incumbe demostrarla a quien la alegue." ${ }^{34}$

Como vemos, con este aporte de la jurisprudencia se logra un avance satisfactorio con relación a la solución de estas situaciones que día a día se siguen presentando, que afectan al consumidor financiero en gran medida y que están evidenciadas en el consolidado de la Superintendencia Financiera de Colombia ${ }^{35}$.

Sin embargo, y para efectos de la discusión que se propone en este escrito, es importante resaltar la preocupación en cuanto a si la protección del consumidor financiero es suficiente en relación con esta realidad y estos eventos producidos por el uso de medios electrónicos. En ese sentido, debe advertirse que el propósito de las políticas públicas para estas actividades debe tener alta prioridad, con el Supervisor como el abanderado de estas luchas, a fin de que se propenda por un consumo y uso responsable de la actividad bancaria a través de los medios electrónicos, que se traduce en el desarrollo de líneas de acción para contribuir con la educación financiera, el fortalecimiento de la defensoría del consumidor financiero, una mayor divulgación de los mecanismos de protección, y más y mejores prácticas de protección propia para que los consumidores conozcan cómo utilizar los productos y servicios del sector financiero ${ }^{36}$.

En Colombia, el entorno electrónico que se implementa en la actividad bancaria exige que exista una protección especial de datos del cliente bancario, es decir, que existan unas prácticas de buen manejo de canales y medios que sea el reflejo de los principios que la ley consagra a favor de los consumidores financieros ${ }^{37}$. Es de resaltar que el uso de canales electrónicos de distribución de servicios en Colombia genera una serie de riesgos que implican para los agentes bancarios un mayor control respecto de estos instrumentos, así como el deber de garantizar la autenticidad, la confidencialidad y la seguridad en las transacciones ${ }^{38}$. Sobre este particular es preciso anotar lo siguiente:

"la actividad bancaria es riesgosa, según Anaya el uso de estos medios por parte de los clientes o consumidores financieros, implica para los agentes bancarios un mayor control respecto de estos instrumentos, así como el deber de garantizar la autenticidad, la confidencialidad y la seguridad en las transacciones". ${ }^{39}$

Lo anterior se encuentra muy ligado a la consideración que hace la Corte Constitucional sobre la actividad bancaria como de interés público, la cual pone un límite a la autonomía de la voluntad que se refleja en las relaciones contractuales entre los bancos y los clientes ${ }^{40}$.

Por otra parte, es preciso anotar que los consumidores también están llamados a cumplir con obligaciones propias de cada relación contractual, pero para lograrlo, primero hay que cumplir con la primera de ellas que es informarse adecuada y oportunamente sobre las características de los productos o servicios que se está próximo a adquirir, cumplir con las indicaciones señaladas por el banco, revisar los términos y condiciones señalados en el contrato.

Sin embargo, dado que es el banco un experto en el negocio ${ }^{41}$, es quien debe procurar que esa información llegue con la mayor precisión, claridad y oportunidad posible, para que el consumidor tenga el conocimiento sobre cómo utilizar el canal y qué derechos y obligaciones giran en torno a su uso. No es una carga del consumidor financiero, sino un derecho que tiene para minimizar los riesgos de la actividad electrónica.

No es suficiente que esta información esté contenida en el acuerdo contractual que se suscribe cuando se apertura una cuenta, o una tarjeta de crédito, es de absoluta relevancia que se oriente al cliente sobre el uso de su instrumento de pago y del canal electrónico para realizar sus transacciones, y que se le transmita la información relativa a los aspectos técnicos y jurídicos que acompañan la relación que nace en ese momento ${ }^{42}$. 
Las medidas que se adoptan dentro del marco regulatorio de la Ley 1328 de 2009, y todos los esfuerzos empleados desde la institucionalidad por la Superintendencia Financiera y la integración con los lineamientos internacionales de protección del consumidor financiero, no pueden ser solo de "papel"; es importante que exista una verdadera protección del consumidor como lo señala la OCDE y todas las organizaciones de la Arquitectura Financiera Internacional en el sentido de que sea visto como un buen sistema financiero, que resulte favorable al consumidor en todo momento, y recibir respuestas oportunas cuando es víctima de fraude por la utilización de estos canales. Considerando lo anterior, es necesario hacer mención de que el cliente, en algunos casos, no recibe respuesta por la clonación de una tarjeta de crédito y la entidad no le ofrece solución para reversar tales operaciones cuando se evidencia que el mismo no las realizó ${ }^{43}$.

En ocasiones, el consumidor usa los mecanismos de protección que la misma entidad le proporciona, lo cual, en la mayoría de ocasiones, resulta ser nulo, en la medida que no dan respuestas ni soluciones al cliente en el término señalado.

Lo que sucede es que estas circunstancias no son evaluadas bajo los parámetros de la diligencia y buena fe; el banco parte de supuestos de hecho y da por cierto que el canal es infalible. Sin embargo, las entidades bancarias no solo deben garantizar a sus clientes unos productos seguros y confiables; deben además ofrecer un trato de respeto y de permanente en educación financiera sobre todo en los casos de hurtos o fraudes a través de canales electrónicos. Deben considerarse como elementos de valoración de esas situaciones la protección de datos que tanto el cliente como la entidad tienen, el cumplimiento de requisitos de seguridad para el uso de tarjetas de crédito y de débito, la actuación de la entidad, la del cliente y el perfil transaccional. De modo que la respuesta por parte de la entidad ante tal situación no sea simplemente de traslado de la responsabilidad por el uso del canal al cliente, sino que este, como consumidor financiero, sienta un acompañamiento que va desde la formación de su relación negocial y durante la ejecución de esta ${ }^{44}$, lo que comprende una adecuada protección.

A criterio propio, la protección al consumidor financiero en los usos de canales electrónicos no está completa, porque se esperaría que si el consumidor está seguro de que actuó de buena fe y dejó claro su diligencia en el uso del canal, su entidad lo acompañe de todas las formas posibles para conocer que sucedió con su dinero y no que, de manera general, le indique y le recuerde cuáles son sus obligaciones asumiendo el banco que sí cumplió con sus deberes, lo anterior teniendo en cuenta la Cartilla de Educación Financiera: construir, avanzar y prosperar ${ }^{45}$.

Lo anterior genera una molestia al consumidor que se aparta de los criterios de la protección contenidos en la Ley 1328 de 2009, porque estos van dirigidos a garantizar, ante todo, la debida diligencia. En ese sentido, sostengo que de alguna manera el banco aprovecha su posición privilegiada para generar confusión en el cliente y no le procura a este una solución, sino que aumenta la controversia y el conflicto. Entonces, en relación con dicho deber, Padilla y Zafra manifiestan que:

"al momento de determinar la debida diligencia de las entidades financieras en sus relaciones con los consumidores financieros, es preciso señalar que aquellas son profesionales y que se encuentran frente a estos en una posición de asimetría contractual, lo cual implica que la diligencia que debe exigírseles a dichas entidades en el cumplimiento de sus obligaciones frente al ordenante o beneficiario ha de ser más estricta. ${ }^{46}$

En ese orden de ideas, a las entidades bancarias se les es exigible un mayor cumplimiento del deber de debida diligencia debido a sus conocimientos especiales e idóneos. Podríamos afirmar que debería trabajarse permanentemente en la fundamentación de la protección del consumidor financiero de cara a la seguridad en el entorno electrónico y a través de experiencias de otros países y desarrollar principios como el equilibrio que debe gobernar en el servicio bancario.

La vigilancia, la buena fe, la debida diligencia ${ }^{47}$ y la necesidad de implementar estrictos niveles de confianza son básicos en la relación del banco con el cliente. Si se exalta la buena fe en la contratación bancaria que tiene como expectativa de parte del cliente la consagración de la confianza como "principio ético" 48 , el 
derecho a recibir información, la debida atención de quejas y reclamos, la calidad ofrecida en los canales de electrónicos $^{49}$, el manejo adecuado de los conflictos de interés y el papel preponderante del Defensor del Consumidor Financiero se contribuye a que la entidad preste mejores servicios en pro del consumidor mismo y de la estabilidad del sector. Si se reúnen estos elementos se estructurarán mejores relaciones con los clientes ${ }^{50}$, basadas en el interés público con el control y vigilancia adecuados, además de buena prestación de servicios financieros.

\section{Conclusiones}

Los canales electrónicos son una gran herramienta para la prestación de los servicios bancarios en Colombia. En este sentido, deben utilizarse en esquemas de seguridad que generen alta confianza para el consumidor financiero.

Las relaciones jurídicas que estructuran el uso de los canales electrónicos deben guardar siempre estrecha relación con la buena fe y los deberes generales de la prestación de los servicios bancarios, para una adecuada protección del consumidor financiero.

La actividad bancaria desarrollada a través de los canales electrónicos debe hacerse bajo los términos de una verdadera protección del consumidor financiero, que acompañe al mismo en todas las operaciones desde el inicio de la relación y durante la ejecución, para que, a través de un trato de respeto, reciba la información adecuada que le permita ejercer sus derechos y apropiarse de su protección.

\section{Bibliografía}

Agustín Madrid Parra, Derecho del sistema financiero y tecnología (Marcial Pons ediciones jurídicas y sociales, 2010). Alejandro Rodríguez Zarate, Análisis económico de la responsabilidad bancaria frente a los fraudes electrónicos: el riesgo provecho, el riesgo creado y el riesgo profesional, 63 Vniversitas, n. ${ }^{\circ}$ 128, 285-314. https://doi.org/10.11144/Jave riana.VJ128.aerb

Asobancaria, Banca de las Oportunidades \& Superintendencia Financiera de Colombia, Educación financiera: construir, avanzar y prosperar (2018). http://bancadelasoportunidades.gov.co/sites/default/files/2017-06/Co nstruir\%2C\%20Avanzar\%20y\%20Prosperar\%20\%20-\%20WEB\%20Completa\%20-\%20Final-final.pdf

Banco Internacional de Reconstrucción y Fomento \& Banco Mundial, Buenas Prácticas para la Protección al Consumidor Financiero (2012). http://documentos.bancomundial.org/curated/es/447021493843704521/pdf 170157-SPANISH-FinConsumerProtection-GoodPractices-SPANISH-FINAL.pdf

Carmen Ligia Valderrama Rojas (ed.), De las garantias: una obligación del productor y proveedor, en Perspectivas del Derecho al Consumo, 227-269 (Universidad Externado de Colombia, 2013).

Celia Weingarten, Los derechos de los consumidores y la fragmentación de la responsabilidad en el proyecto de reforma y unificación de los Códigos Civil y Comercial, Revista Jurídica UCES, 158-169 (2007). http://dspace.uces.edu.ar: 8180/jspui/bitstream/123456789/2144/1/Los_derechos_Weingarten.pdf

Celina Patricia Anaya Saade, Riesgos en las transacciones electrónicas bancarias. Una carga que debe ser asumida por la banca. 11 Revista Mercatoria, n. 1², 287-331 (2012). https://revistas.uexternado.edu.co/index.php/emerca/ article/view/3206

Circular 052 de 2007 [Superintendencia Financiera de Colombia]. Requerimientos mínimos de seguridad y calidad en el manejo de información a través de medios y canales de distribución de productos y servicios para clientes y usuarios. 15 de octubre de 2007.

Circular Básica Jurídica 029. 6 de octubre de 2014 (Colombia). 
Constanza Blanco, La información como instrumento de protección de los consumidores, los consumidores financieros y los inversionistas consumidores, 11 Opinión Jurídica, 21, 135-152 (2012). https://revistas.udem.edu.co/index.php /opinion/article/view/532

Corte Constitucional de Colombia. Sentencia T-517 de 2006 (M. P. Marco Gerardo Monroy cabra; 7 de julio de 2006).

Corte Suprema de Justicia. Sala de Casación Civil. Sentencia SC18614-2016 (M. P. Ariel Salazar; 19 de diciembre de 2016).

Decreto 410 de 1971. Código de Comercio. 27 de marzo de 1971 (Colombia).

Decreto Único 2555 de 2010. Por el cual se recogen y reexpiden las normas en materia del sector financiero, asegurador y del mercado de valores y se dictan otras disposiciones. 15 de julio de 2010 (Colombia).

Delegatura de Asuntos jurisdiccionales- Superintendencia Financiera de Colombia. 2016122931. Caso Heriberto Linero Vs Bancoomeva. 22 de noviembre de 2016 (Colombia).

Edgar Cortes, La culpa contractual en el sistema jurídico latinoamericano (Universidad Externado de Colombia, 2009).

Eliana Fernanda Romero Vivas, El principio implícito de la buena fe y el trato justo como mecanismo modificatorio del contrato de franquicia dentro del derecho norteamericano, Anuario de Derecho Privado, n. ${ }^{\circ} 54,1-32$ (2015). http s://www.redalyc.org/pdf/3600/360043572002.pdf

Erick Rincón, Manual de Derecho de Comercio Electrónico e Internet (Editorial Universidad del Rosario, 2006).

II Jorge Suescun, Derecho Privado Estudios de Derecho Civil y Comercial Contemporáneo (2.. ed., 2003).

Jorge Alberto Padilla Sánchez \& Málory Zafra Sierra, Responsabilidad de los establecimientos bancarios por el pago de cheques falsos o alterados en Colombia, Revista de Derecho Privado, n. ${ }^{\circ} 32,383-420$ (2017). https://doi.org/10 $.18601 / 01234366 . n 32.13$

Jorge Armando Corredor Higuera, La armonización en materia de protección al consumidor financiero en América Latina, 48 Boletín Mexicano de Derecho Comparado, n. ${ }^{\circ}$ 144, 931-972 (2015). https://doi.org/10.22201/iij. 24484873e.2015.144.4956

Jorge Goddard, Obligaciones y contratos en el derecho contemporáneo (Universidad de la Sabana, Colombia, 2010). https://intellectum.unisabana.edu.co/bitstream/handle/10818/27762/LIBRO\%20OBLIGACIONES \%20Y\%20CONTRATOS\%20FINAL\%20PDF.pdf?sequence=1

Ley 1328 de 2009. Ley de materia financiera, de seguros y de mercado de valores. 15 de julio de 2009 (Colombia)

Ley 1480 de 2011. Por medio de la cual se expide el Estatuto del Consumidor y se dictan otras disposiciones. 12 de octubre de 2011. D. O. No. 48.220.

Martha Lucía Neme Villarreal, Buena fe Subjetiva y buena fe objetiva: equivocos a los que conduce la falta de claridad en las distinciones de tales conceptos, Revista De Derecho Privado, n. $17,45-76$ (2009). https://revistas.uexternado .edu.co/index.php/derpri/article/view/410

Martha Lucía Neme Villarreal, El principio de la buena fe contractual en el sistema jurídico colombiano, Revista de Derecho Privado Externado, n. ${ }^{\circ} 11,79-126$ (2006). https://revistas.uexternado.edu.co/index.php/derpri/articl e/view/575

Sergio Rodríguez Azuero, Contratos bancarios: su significación en América Latina (6.. ed., Legis, 2009).

Superintendencia Financiera de Colombia, Información Estadística Semestral. Aprenda con la Super (2017). https:// www.superfinanciera.gov.co/inicio/informacion-estadistica-semestral-11131

\section{Notas}

1 Artículo de reflexión. Este artículo es resultado de un proyecto de investigación titulado Pertinencia de los mecanismos de protección legal del consumidor financiero por el uso de canales de distribución de productos y servicios del sector bancario en Colombia, financiado por la Vicerrectoría de Investigación de la Universidad del Magdalena, en la convocatoria denominada Capital Semilla.

2 Agustín Madrid Parra, Derecho del sistema financiero y tecnología (Marcial Pons ediciones jurídicas y sociales, 2010).

3 Circular Básica Jurídica 029. Capítulo 1. Título 2. Numeral. 1.3. 6 de octubre de 2014 (Colombia). 
Circular 052 de 2007 [Superintendencia Financiera de Colombia]. Requerimientos mínimos de seguridad y calidad en el manejo de información a través de medios y canales de distribución de productos y servicios para clientes y usuarios. 15 de octubre de 2007.

$5 \quad$ Circular 052 de 2007. La definición de canal de distribución se encuentra en la sección 2.1.1

6 Sergio Rodríguez Azuero, Contratos bancarios: su significación en América Latina (6.a ed., Legis, 2009).

7 Decreto Único 2555 de 2010. Por el cual se recogen y reexpiden las normas en materia del sector financiero, asegurador y del mercado de valores y se dictan otras disposiciones. 15 de julio de 2010 (Colombia). Título 15 capítulo 1, artículo 2.1.15.1.1.

8 Artículo 2, literal b.

9 Circular Básica Jurídica 029.6 de octubre de 2014 (Colombia).

10 Sergio Rodríguez Azuero, op. cit., 189.

11 Constanza Blanco, La información como instrumento de protección de los consumidores, los consumidores financieros y los inversionistas consumidores, 11 Opinión Jurídica, 21, 135-152 (2012).

12 Sergio Rodríguez Azuero, op. cit., 306.

13 II Jorge Suescun, Derecho Privado Estudios de Derecho Civil y Comercial Contemporáneo (2.a ed., 2003).

14 Sergio Rodríguez Azuero, op. cit., 189.

15 Alejandro Rodríguez Zarate, Análisis económico de la responsabilidad bancaria frente a los fraudes electrónicos: el riesgo provecho, el riesgo creado y el riesgo profesional, 63 Vniversitas, n. ${ }^{\circ} 128,285-314$.

16 Banco Internacional de Reconstrucción y Fomento \& Banco Mundial, Buenas Prácticas para la Protección al Consumidor Financiero (2012).

17 Ley 1480 de 2011. Por medio de la cual se expide el Estatuto del Consumidor y se dictan otras disposiciones. 12 de octubre de 2011. D. O. No. 48.220. Artículo 57.

18 Martha Lucía Neme Villarreal, Buena fe Subjetiva y buena fe objetiva: equívocos a los que conduce la falta de claridad en las distinciones de tales conceptos, Revista De Derecho Privado, n. ${ }^{\circ}$ 17, 45-76 (2009).

19 Eliana Fernanda Romero Vivas, El principio implicito de la buena fe y el trato justo como mecanismo modificatorio del contrato de franquicia dentro del derecho norteamericano, Anuario de Derecho Privado, n. ${ }^{\circ}$ 54, 1-32 (2015).

20 Jorge Goddard, Obligaciones y contratos en el derecho contemporáneo (Universidad de la Sabana, Colombia, 2010).

21 Jorge Armando Corredor Higuera, La armonización en materia deprotección al consumidor financiero en América Latina, 48 Boletín Mexicano de Derecho Comparado, n. ${ }^{\circ}$ 144, 931-972 (2015).

22 Constitución Política de Colombia [Const]. Art. 335.7 de julio de 1991 (Colombia).

23 Decreto 410 de 1971. Código de Comercio. 27 de marzo de 1971 (Colombia).

24 Constanza Blanco, op. cit.

25 Jorge Armando Corredor Higuera, op. cit.

26 Constanza Blanco, op. cit.

27 Este caso fue radicado ante la Delegatura de Asuntos Jurisdiccionales ante la Superintendencia Financiera de Colombia con el número 2016122931 de 22 de noviembre de 2016. Caso Heriberto Linero Roa vs Bancoomeva S.A.

28 En este escenario se parte del hecho de que la tercera hipótesis no se cumple, porque el cliente ha sido cuidadoso con el uso del canal.

29 Esto está señalado en el artículo 335 de la constitución política de Colombia.

30 El llamado régimen especial y de carácter público se crea para que el Estado pueda intervenir en las actividades en la que estén de por medio intereses de carácter general y que requieran protección, y que, en el caso de los bancos, está dado por el Estatuto Orgánico Financiero y demás normas y reglamentaciones complementarias.

31 Edgar Cortes, La culpa contractual en el sistema jurídico latinoamericano, 63 (Universidad Externado de Colombia, 2009).

32 Martha Lucía Neme Villarreal, El principio de la buena fe contractual en el sistema jurídico colombiano, Revista de Derecho Privado Externado, n. ${ }^{\circ} 11,79-126$ (2006).

33 Corte Suprema de Justicia. Sala de Casación Civil. Sentencia SC18614-2016 (M. P. Ariel Salazar; 19 de diciembre de 2016).

34 Corte Suprema de Justicia. Sala de Casación Civil. Sentencia SC18614-2016 (M. P. Ariel Salazar; 19 de diciembre de 2016).

35 Superintendencia Financiera de Colombia., Información Estadística Semestral. Aprenda con la Super, (2017).

36 Entrevista realizada al Coordinador del Grupo de Trabajo, Supervisión, Publicidad de Educación Financiera de la Superintendencia Financiera de Colombia. Señor Henry Steven Giraldo Murcia.

37 Carmen Ligia Valderrama Rojas (ed.), De las garantias: una obligación del productor y proveedor, en Perspectivas del Derecho al Consumo, 227-269 (Universidad Externado de Colombia, 2013).

38 Erick Rincón, Manual de Derecho de Comercio Electrónico e Internet (Editorial Universidad del Rosario, 2006). 
39 Celina Patricia Anaya Saade, Riesgos en las transacciones electrónicas bancarias. Una carga que debe ser asumida por la banca. 11 Revista Mercatoria, n. 1², 287-331 (2012).

40 Corte Constitucional de Colombia. Sentencia T-517 de 2006 (M. P. Marco Gerardo Monroy cabra; 7 de julio de 2006).

41 Sergio Rodríguez Azuero, op. cit., 190.

42 Constanza, Blanco. op. cit.

43 Este caso le ocurrió a la suscrita en particular

44 El fundamento de esta posición coincide con la información recibida por parte de la Defensora del Consumidor Financiero del Banco Colpatria, quien amablemente compartió su experiencia con datos obtenidos desde la realidad de su ejercicio y que se consideran aportes para esta investigación. Consuelo Rodríguez, Defensor Del Consumidor Financiero Del Banco Colpatria.

45 Asobancaria, Banca de las Oportunidades \& Superintendencia Financiera de Colombia, Educación financiera: construir, avanzar y prosperar (2018).

46 Jorge Alberto Padilla Sánchez \& Málory Zafra Sierra, Responsabilidad de los establecimientos bancarios por el pago de cheques falsos o alterados en Colombia, Revista de Derecho Privado, n. ${ }^{\circ} 32,383-420$ (2017).

47 Ley 1328 de 2009. Ley de materia financiera, de seguros y de mercado de valores. 15 de julio de 2009 (Colombia).

48 Celia Weingarten, Los derechos de los consumidores y la fragmentación de la responsabilidad en el proyecto de reforma $y$ unificación de los Códigos Civily Comercial, Revista Jurídica UCES, 158-169 (2007).

49 Martha Lucía Neme Villarreal, op. cit.

50 Jorge Armando Corredor Higuera, op. cit.

\section{Licencia Creative Commons CC BY 4.0}

Para citar este articulo/To cite this article: Celina Patricia Anaya Saade, Protección del consumidor financiero en Colombia en el uso de canales electrónicos bancarios, 69 Vniversitas (2020). https://doi.org//10.11144/Ja veriana.vj69.pcms 